\title{
Unplanned Terminal Sacrifice
}

National Cancer Institute

\section{Source}

National Cancer Institute. Unplanned Terminal Sacrifice. NCI Thesaurus. Code C106580.

An indication that the subject was sacrificed prior to the end of the planned treatment period, and the subject was not otherwise moribund. 